1 Lokman Hekim Hospital, Department of Cardiology, Van, Turkey ${ }^{2}$ Mersin University, Department of Endocrinology, Mersin, Turkey ${ }^{3}$ Mersin University, Department of Cardiology, Mersin, Turkey ${ }^{4}$ Lokman Hekim Hospital, Department of Internal Medicine, Van, Turkey
Correspondence to: Mustafa Yurtdaş Lokman Hekim Van Hastanesi, Kardiyoloji Bölümü 65200, Van, Turkey

mustafayurtdas@yahoo.com

Received on Aug/26/2012 Accepted on Oct/25/2012

\section{Assessment of the elasticity properties of the ascending aorta in patients with subclinical hypothyroidism by tissue Doppler imaging}

\author{
Avaliação das propriedades de elasticidade da aorta ascendente \\ por Doppler tecidual em pacientes com hipotireoidismo subclínico
}

Mustafa Yurtdaș ${ }^{1}$, Ramazan Gen², Turkay Özcan³ ${ }^{3}$ Mehmet Kasım Aydın

\begin{abstract}
Objective: We aimed to investigate whether aortic elastic properties were affected in subclinical hypothyroidism (SCH) by using tissue Doppler imaging (TDI). Subjects and methods: Forty-three patients with newly diagnosed $\mathrm{SCH}$ and forty-eight healthy controls were included to the study. Systolic and diastolic diameters of the ascending aorta were measured by M-mode transthoracic echocardiography, and the upper wall velocities of ascending aorta and mitral annulus velocities were measured by TDI. Aortic stiffness index (ASI) and aortic distensibility were computed using the formulas accepted in literature. Results: The clinical and demographic features of both groups were comparable. Aortic distensibility was significantly lower, and ASI was significantly higher in $\mathrm{SCH}$ patients than in controls. Systolic aortic upper wall velocity (Sao) was also significantly lower in $\mathrm{SCH}$ patients. Early (Eao) and late diastolic aortic upper wall (Aao) velocities did not differ between the two groups. Mitral annulus (Sm, Em, and Am) velocities were also similar between the groups. Sao was negatively correlated with ASI, and positively correlated with aortic distensibility. TSH level was positively correlated with ASI, total cholesterol and low-density lipoprotein-cholesterol, and negatively correlated with aortic distensibility and Sao. Conclusions: In this study, our results showed that $\mathrm{SCH}$ is associated with impaired elasticity of the ascending aorta. Elastic properties of the ascending aorta can be directly evaluated by the reproducibly measurement of the upper wall movements of the ascending aorta byTDI in SCH patients. Arq Bras Endocrinol Metab. 2013;57(2):132-8
\end{abstract}

\section{Keywords}

Tissue Doppler imaging; subclinical hypothyroidism; stiffness

\section{RESUMO}

Objetivo: Nosso objetivo foi investigar se as propriedades elásticas da aorta são afetadas no hipotireoidismo subclínico (HSC), utilizando o Doppler tecidual (UDT). Sujeitos e métodos: Quarenta e três pacientes com diagnóstico recente de HSC e 48 indivíduos saudáveis foram incluídos no estudo. Os diâmetros sistólico e diastólico da aorta foram medidos por ecocardiografia transtorácica modo $\mathrm{M}$ e as velocidades de fluxo da parede superior da aorta ascendente e de fluxo transvalvar mitral foram medidas por UDT. 0 índice de rigidez da aorta (IRA) e a distensibilidade aórtica foram calculados usando fórmulas aceitas na literatura. Resultados: As características clínicas e demográficas dos dois grupos foram comparáveis. A distensibilidade aórtica foi significativamente menor e IRA significativamente maior nos pacientes com HSC do que nos controles. A velocidade de fluxo sistólico na parede aórtica superior (Sao) foi significantemente menor em pacientes com HSC. A velocidade de fluxo diastólico inicial (Eao) e tardio (Aao) na parede aórtica superior e as velocidades de fluxo transvalvar ( $\mathrm{Sm}, \mathrm{Em}$ e Am) não diferiram entre os dois grupos. Sao foi negativamente correlacionada com IRA e positivamente correlacionada com a distensibilidade aórtica. $\mathrm{O}$ nível de TSH foi positivamente correlacionado com IRA, colesterol total e lipoproteína de baixa densidade-colesterol e negativamente correlacionado com a distensibilidade aórtica e Sao. Conclusões: Os resultados do presente estudo demonstraram que o HSC é associado com elasticidade deficiente da aorta ascendente. Propriedades elásticas da aorta ascendente podem ser diretamente avaliadas por medições reprodutíveis dos movimentos da parede superior da aorta por UDT em pacientes com HSC. Arq Bras Endocrinol Metab. 2013;57(2):132-8

Descritores

Doppler tissular; hipotireoidismo subclínico; rigidez 


\section{INTRODUCTION}

S ubclinical hypothyroidism $(\mathrm{SCH})$ is defined as an elevated serum level of thyroid stimulating hormone $(\mathrm{TSH})$ with normal free thyroid values $(1,2)$. The prevalence of $\mathrm{SCH}$ has been reported to be between $4 \%$ and $10 \%$ in adult population samples $(2,3)$. Coronary artery disease $(\mathrm{CAD})$ and cardiovascular mortality are increased in patients with $\mathrm{SCH}$, particularly in those with higher TSH levels $(4,5)$.

Functional properties of large arteries are important both for the normal function of the artery itself and for left ventricular function (6). Previous studies have shown that increased aortic stiffness and decreased distensibility, which are impairments in the elastic properties of the aorta, are presented together with premature atherosclerosis and CAD (7-10). Several procedures have been used for the determination of aortic stiffness and/or distensibility, such as magnetic resonance imaging, angiography, applanation tonometry, velocity vector imaging (VVI) (9-12). But the vast majority of these techniques are invasive and time-consuming and may require complex equipment and training. Conventional and tissue Doppler imaging (TDI) echocardiography have been shown to be useful methods in the evaluation of global ventricular functions and elastic properties of the aorta (13-17). Although increased arterial stiffness index has been formerly shown in various patient groups, including those with $\mathrm{CAD}$, diabetes mellitus (DM), overt hypothyroidism, and SCH on different vascular beds and in different sites such as the radial artery, carotid artery, and aorta (14-20), as far as we know, no report has evaluated elastic properties of the ascending aorta by TDI in patients with SCH.

To clarify this issue, we aimed to investigate, using TDI, whether elastic properties of the ascending aorta are affected in patients with $\mathrm{SCH}$.

\section{SUBJECTS AND METHODS}

\section{Study population}

Newly detected asymptomatic or mild symptomatic (such as those presenting dry hair or skin, cold intolerance, forgetfulness, constipation, depression, and weakness) SCH patients with increased serum TSH $(4.2<\mathrm{TSH}<20.0 \mathrm{mIU} / \mathrm{mL})$, normal free T3 (FT3) and free T4 (FT4) levels were recruited for the study. Forty- -three patients with SCH in at least two thyroid hormonal profiles measured 3 months before study were examined prospectively. The control group (11 males, 37 females; mean age, $42 \pm 11$ years old) consisted of healthy volunteers with normal FT3 (normal range: 2.0-4.4 $\mathrm{pg} / \mathrm{mL}$ ), FT4 (normal range: $0.93-1.7 \mathrm{ng} / \mathrm{dL}$ ), and TSH (normal range: $0.27-4.2 \mathrm{mIU} / \mathrm{mL}$ ) levels matched for age, sex, and body mass index (BMI). The exclusion criteria were previous history of thyroid disease, valvular heart disease, cardiac rhythm disturbance, heart failure, arterial hypertension, pulmonary hypertension, pregnancy, hepatic or renal disease, respiratory disease, DM, neurological or psychological disease, and malignancy. Also, CAD was excluded based on normal results of the exercise stress echo test applied to all study members. None of the subjects received medications that could influence heart rate and serum thyroid hormone levels. Physical examination, medical history, inflammatory markers, and electrocardiogram were normal for all participants. The study protocol was approved by the Research Review Board of Mersin University, and informed consent was obtained from all participants.

\section{Echocardiographic study}

Echocardiographic examinations were performed by using a 1.5-3.4 MHz probe with Vivid-5S echocardiography device. All patients were examined in left lateral decubitus by M-mode, two-dimensional echocardiography and TDI. All echocardiographic findings were analysed by two cardiologists who were blinded to patients' clinical and biochemical status. Left ventricular (LV) end-diastolic dimension, thickness of interventricular septum (IVS) and posterior wall (PW) were calculated at the onset of the electrocardiographic $\mathrm{Q}$ wave. LV end-systolic dimension was calculated at the time of the smallest LV diameter. LV end-diastolic volume, end-systolic volume, stroke volume, and ejection fraction were obtained from two- or apical four-chamber views by means of the modified Simpson method. Cardiac output was estimated as a product of stroke volume and heart rate. Left ventricular myocardial weight (LVMW) was measured using the formula by Devereux and cols. (21). Body surface area (BSA) was identified according to the method defined by DuBois and DuBois (22). LV mass index was measured as LVMW/BSA (23). Systemic arterial blood pressure (BP) was measured at the right brachial artery by manual sphygmomanometry in supine position, simultaneously with the echocardiographic 
examination of the ascending aorta. BP was measured three times on each occasion at 3-minute intervals and averaged. Pulse pressure (PP) was obtained by subtracting diastolic blood pressure (DBP) from systolic blood pressure (SBP). Systolic and diastolic inner diameters of the ascending aorta were recorded by M-mode echocardiography $3 \mathrm{~cm}$ above the aortic valve, in a parasternal long axis image. Aortic systolic diameter (AoS) was measured at the maximum anterior motion of the aorta, and aortic diastolic diameter (AoD) was measured at the peak of the QRS complex on the recorded electrocardiogram, simultaneously (Figure 1). Distensibility and stiffness index of the ascending aorta were calculated by using the following formulaes (14-17).

Aortic distensibility $=2 \mathrm{X}(\mathrm{AoS}-\mathrm{AoD}) /(\mathrm{SBP}-$ DBP) X AoD $\left(10^{-6} \cdot \mathrm{cm}^{2} \cdot\right.$ dyn $\left.^{-1}\right)$,

Aortic stiffness index $=\ln (\mathrm{SBP} / \mathrm{DBP}) /[(\mathrm{AoS}$ - AoD) / AoD] (pure number), ln = natural logarithm.

The indexes of aortic systolic and diastolic diameters, and pulsatile change $\left(\mathrm{cm} / \mathrm{m}^{2}\right)$ for each subject were estimated by dividing AoS, AoD and the pulsatile change in aortic diameter (PAod) by BSA, respectively. Then, the echocardiographic device was switched to theTDI mode, and aortic superior wall velocities in systole (Sao), early diastole (Eao) and late diastole (Aao) were estimated at the same point used in the M-mode measurements (Figure 2). In addition, from the apical window, mitral annulus velocities in systole $(\mathrm{Sm})$, early diastole $(\mathrm{Em})$ and late diastole $(\mathrm{Am})$ were calculated. All the parameters were computed and the average of five consecutive cycles was calculated.

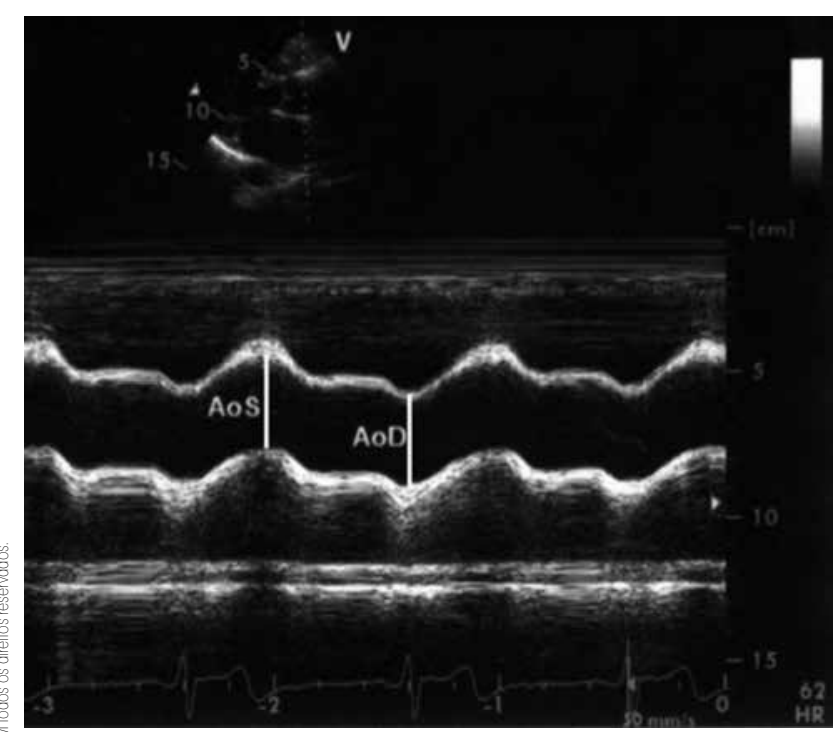

Figure 1. Systolic and diastolic diameter measurements of the ascending aorta with M-mode echocardiography. AoS: aortic systolic diameter; AoD: aortic diastolic diameter.

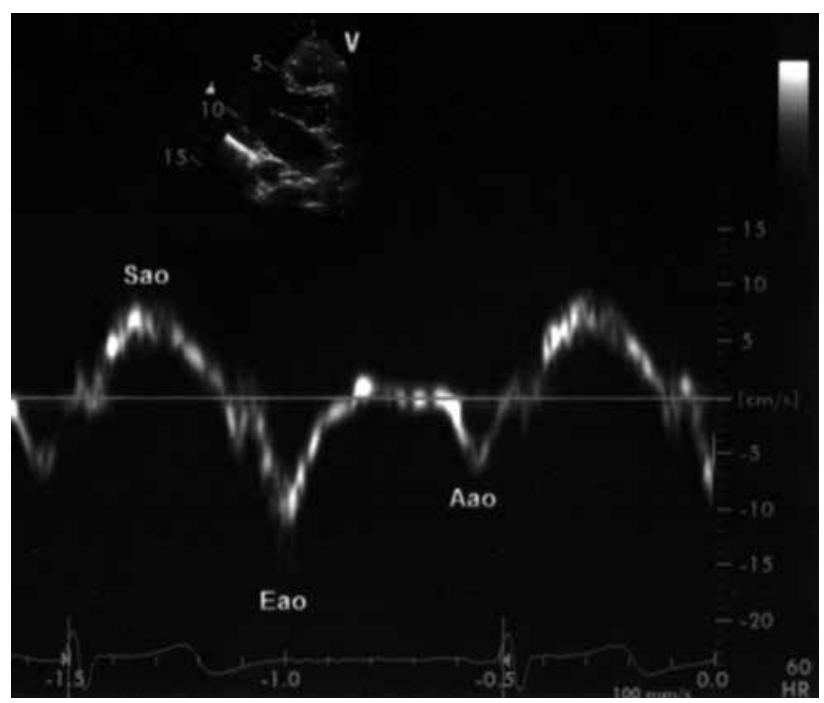

Figure 2. Aortic upper wall velocity measurements with tissue Doppler imaging. Sao: systolic aortic upper wall velocity; Eao: early diastolic aortic upper wall velocity; Aao: late diastolic aortic upper wall velocity.

\section{Biochemical and hormonal analysis}

Blood samples were withdrawn after 12 hours of overnight fasting for FT3, FT4, TSH, total cholesterol (TC), triglyceride (TG), high-density lipoprotein-cholesterol (HDL-C). Assays for TC, TG, HDL-C were performed using a Cobas Integra 800 automated analyzer (Roche Diagnostics, Manheim, Germany). Serum low-density lipoprotein-cholesterol (LDL-C) was calculated according to Friedewald's Formula (24). Serum FT3, FT4, and TSH levels were measured using the Modular E170 automated analyzer (Roche Diagnostics, Manheim, Germany). The sensitivity of the assays for FT3, FT4, and TSH was $0.260 \mathrm{pg} / \mathrm{mL}, 0.023$ $\mathrm{ng} / \mathrm{dL}$, and $0.005 \mathrm{mIU} / \mathrm{mL}$, respectively.

\section{Reproducibility}

Interobserver variability of aortic elastic measurements was measured as the difference between two measurements of the same patient by two different cardiologists divided by the mean value. Intraobserver variability was calculated as the difference between two measurements of the same patient by a single cardiologist divided by the mean value. Intraobserver and interobserver variability were less than $5 \%$ for all aortic elasticity measurements in the total study population.

\section{Statistical analysis}

Statistical analysis was performed using the SPSS software package (Version 15.0, SPSS Inc, Chicago, IL, 
USA). Kolmogorov-Smirnov test was used to investigate whether the distribution of measurements was normal or not. Categorical variables were expressed as percentages, and compared using the Chi-square test. Continuous variables were expressed as means \pm SD. To compare the variables that showed normal distribution in the two groups, independent $t$-test was used. In contrast, for the variables that did not show normal distribution, Mann-Whitney U test was used. Linear correlations between measurements in both groups were determined by Pearson's correlation. Two-tailed tests were used to test all hypotheses, and $p$-value of $<0.05$ was considered significant.

\section{RESULTS}

The baseline clinical and demographic features, and FT3, FT4, TSH levels of the patients and controls are shown in Table 1. Demographic characteristics of the two groups were similar. There were no significant differences in SBP, DBP, PP, and heart rate between the two groups. The participants with $\mathrm{SCH}$ demonstrated an increase in serum TSH above the normal upper limit $(8.9 \pm 2.8 \mathrm{mUI} / \mathrm{mL}, \mathrm{p}<0.001)$, and had higher TC and LDL-C than those of controls $(\mathrm{p}=0.009, \mathrm{p}=$ 0.003 ; respectively). Echocardiographic variables of the groups are shown in Table 2. Mean left ventricular dimensions and volumes, IVS, and PW thickness were not significantly different between the groups. In addition, LVMI, LVEF, and cardiac output of both groups were also similar.

Aortic stiffness index, aortic distensibility, aortic diameters, and TDI measurements of the two groups are summarized in Table 3 . Aortic stiffness index was significantly higher $(4.0 \pm 0.4$ vs. $3.4 \pm 0.5 ; \mathrm{p}<0.001)$ and aortic distensibility was significantly lower $(0.99$ \pm 0.6 vs. $1.83 \pm 1.1 \times 10^{-6} . \mathrm{cm}^{2}$.dynes $\left.{ }^{-1} ; \mathrm{p}<0.001\right)$ in patients with $\mathrm{SCH}$ than in those who were euthyroid. The values of AoS and AoD were comparable between SCH patients and controls. PAod, however, was significantly lower in patients with SCH compared with the controls $(0.11 \pm 0.09$ vs. $0.17 \pm 0.06 ; \mathrm{p}=0.004)$. Sao was also significantly lower in patients with $\mathrm{SCH}$ than in controls $(6.6 \pm 3.9$ vs. $9.2 \pm 4.1 \mathrm{~cm} / \mathrm{sec} ; \mathrm{p}=$ 0.003 ). Early diastolic aortic upper wall velocity (Eao) and late diastolic aortic upper wall velocity (Aao), and mitral annulus systolic $(\mathrm{Sm})$, early diastolic $(\mathrm{Em})$, and late diastolic wave $(\mathrm{Am})$ velocities were similar in the two groups.
Table 1. Clinical and demographic characteristics and thyroid hormone levels of both groups

\begin{tabular}{lccc}
\hline & $\begin{array}{c}\text { SCH } \\
\text { patients } \\
(\mathbf{n = 4 3 )}\end{array}$ & $\begin{array}{c}\text { Controls } \\
(\mathbf{n = 4 8 )}\end{array}$ & P \\
\hline Sex (male/female) & $7 / 36$ & $11 / 37$ & 0.599 \\
Age (years) & $43 \pm 9$ & $42 \pm 11$ & 0.539 \\
Body mass index (kg/m²) & $28 \pm 3$ & $27 \pm 4$ & 0.449 \\
Smoking (\%) & 23 & 35 & 0.253 \\
SBP (mmHg) & $128 \pm 9$ & $126 \pm 9$ & 0.514 \\
DBP (mmHg) & $75 \pm 7$ & $73 \pm 8$ & 0.106 \\
Pulse pressure (mmHg) & $52 \pm 9$ & $53 \pm 13$ & 0.734 \\
Mean arterial pressure (mmHg) & $93 \pm 6$ & $90 \pm 7$ & 0.107 \\
Heart rate (per/min) & $70 \pm 13$ & $73 \pm 11$ & 0.179 \\
Total cholesterol (mg/dL) & $217 \pm 18$ & $207 \pm 17$ & 0.009 \\
Triglycerides (mg/dL) & $153 \pm 30$ & $143 \pm 31$ & 0.112 \\
LDL-C (mg/dL) & $141 \pm 20$ & $130 \pm 17$ & 0.003 \\
HDL-C (mg/dL) & $46 \pm 6$ & $48 \pm 7$ & 0.147 \\
Free T3 (pg/mL) & $2.79 \pm 0.63$ & $2.91 \pm 0.72$ & 0.408 \\
Free T4 (ng/dL) & $1.13 \pm 0.22$ & $1.21 \pm 0.29$ & 0.145 \\
TSH (mUl/mL) & $8.9 \pm 2.8$ & $1.4 \pm 0.3$ & $<0.001$ \\
\hline
\end{tabular}

SBP: systolic blood pressure; DBP: diastolic blood pressure; LDL-C: low-density lipoprotein cholesterol; HDL-C: high-density lipoprotein cholesterol; TSH: thyroid stimulating hormone; SCH: subclinical hypothyroidism.

Table 2. Echocardiographic variables of SCH patients and controls

\begin{tabular}{lccc}
\hline & $\begin{array}{c}\text { SCH } \\
\text { patients } \\
(\mathbf{n = ~ 4 3 )}\end{array}$ & $\begin{array}{c}\text { Controls } \\
(\mathbf{n}=\mathbf{4 8})\end{array}$ & $\mathbf{P}$ \\
\hline LVEDD $(\mathrm{mm})$ & $50.6 \pm 5.1$ & $49.5 \pm 4.7$ & 0.308 \\
LVESD (mm) & $33.9 \pm 3.6$ & $32.8 \pm 3.7$ & 0.190 \\
IVST (mm) & $9.6 \pm 1.5$ & $9.2 \pm 1.3$ & 0.276 \\
PWT (mm) & $8.5 \pm 1.4$ & $8.1 \pm 1.2$ & 0.204 \\
LVMI (g/m²) & $82.9 \pm 30.9$ & $73.8 \pm 22.3$ & 0.114 \\
LVEDV (mL) & $101.5 \pm 10.1$ & $99.8 \pm 9.5$ & 0.425 \\
LVESV (mL) & $35.8 \pm 5.3$ & $33.7 \pm 6.4$ & 0.098 \\
LVEF (\%) & $64.7 \pm 4.1$ & $66.3 \pm 4.3$ & 0.068 \\
CO (L/min) & $4.6 \pm 1.0$ & $4.8 \pm 0.9$ & 0.222 \\
\hline
\end{tabular}

LVEDD: left ventricular end-diastolic diameter; LVESD: left ventricular end-systolic diameter; IVST: interventricular septum thickness; PWT: posterior wall thickness; LVMI: left ventricular mass index; LVEDV: left ventricular end-diastolic volume; LVESV: left ventricular end-systolic volume; LVEF: left ventricular ejection fraction; CO: cardiac output; SCH: subclinical hypothyroidism.

The relationships between aortic stiffness index and aortic distensibility to TDI measurements were evaluated in the SCH group. Sao was negatively correlated with aortic stiffness index $(\mathrm{r}=-0.612, \mathrm{p}<0.001)$, and positively correlated with aortic distensibility $(\mathrm{r}=$ $0.565, \mathrm{p}<0.001)$. The relationships between aortic stiffness index, aortic distensibility, Sao, TC, LDL-C 
to $\mathrm{TSH}$ value in the $\mathrm{SCH}$ group are shown in table 4. TSH was positively correlated with TC $(\mathrm{r}=0.631$, $\mathrm{p}<0.001)$, LDL-C $(\mathrm{r}=0.653, \mathrm{p}<0.001)$, and aortic stiffness index $(\mathrm{r}=0.524, \mathrm{p}<0.001)$, and negatively correlated with aortic distensibility $(\mathrm{r}=-0.436, \mathrm{p}=$ $0.003)$ and Sao $(\mathrm{r}=-0.582, \mathrm{p}<0.001)$. There were no correlations between aortic upper wall velocities (Sao, Eao, Aao) and mitral annulus velocities (Sm, Em, Am). No correlations were observed in the control group.

Table 3. Aortic stiffness index, distensibility, M-mode, and TDI measurements in SCH patients and controls

\begin{tabular}{lccc}
\hline & $\begin{array}{c}\text { SCH } \\
\text { patients } \\
(\mathbf{n = 4 3})\end{array}$ & $\begin{array}{c}\text { Controls } \\
(\mathbf{n = 4 8})\end{array}$ & $\mathbf{P}$ \\
\hline Aortic stiffness index & $4.0 \pm 0.4$ & $3.4 \pm 0.5$ & $<0.001$ \\
Distensibility $\left(10^{-6} . \mathrm{cm}^{2}\right.$.dynes- $\left.{ }^{-}\right)$ & $0.99 \pm 0.6$ & $1.83 \pm 1.1$ & $<0.001$ \\
Aortic systolic diameter $(\mathrm{cm})$ & $3.12 \pm 0.21$ & $3.07 \pm 0.33$ & 0.442 \\
Aortic diastolic diameter (cm) & $3.00 \pm 0.22$ & $2.91 \pm 0.34$ & 0.132 \\
Pulsatile change in aortic & $0.11 \pm 0.09$ & $0.17 \pm 0.06$ & 0.004 \\
diameter (cm) & & & \\
Aortic systolic index (cm/m²) & $1.59 \pm 0.16$ & $1.57 \pm 0.15$ & 0.493 \\
Aortic diastolic index (cm/m²) & $1.54 \pm 0.15$ & $1.49 \pm 0.14$ & 0.155 \\
Pulsatile change index (cm/m²) & $0.06 \pm 0.04$ & $0.09 \pm 0.03$ & 0.003 \\
Aortic upper wall velocities & & & \\
Sao (cm/sec) & $6.6 \pm 3.9$ & $9.2 \pm 4.1$ & 0.003 \\
Eao (cm/sec) & $6.5 \pm 3.1$ & $7.7 \pm 3.4$ & 0.103 \\
Aao (cm/sec) & $7.4 \pm 3.5$ & $7.8 \pm 3.7$ & 0.557 \\
Mitral annulus velocities & & & \\
Sm (cm/sec) & $6.5 \pm 3.4$ & $7.4 \pm 3.3$ & 0.190 \\
Em (cm/sec) & $9.9 \pm 4.9$ & $10.4 \pm 5.3$ & 0.643 \\
Am (cm/sec) & $8.0 \pm 2.3$ & $7.6 \pm 2.4$ & 0.417 \\
Em/Am & $1.4 \pm 0.9$ & $1.5 \pm 0.7$ & 0.735 \\
\hline
\end{tabular}

Sao: systolic aortic upper wall velocity; Eao: early diastolic aortic upper wall velocity; Aao: late diastolic aortic upper wall velocity; Sm: systolic mitral annulus velocity; Em: early diastolic mitral annulus velocity; Am: late diastolic mitral annulus velocity; TDI: tissue Doppler imaging; SCH: subclinical hypothyroidism.

Table 4. Relationships between aortic stiffness index, aortic distensibility, Sao, TC, LDL-C and TSH value in SCH patients

\begin{tabular}{lcc}
\hline & \multicolumn{2}{c}{ TSH value } \\
\cline { 2 - 3 } & $\mathbf{r}$ & $\mathbf{p}$ \\
\hline Aortic stiffness index & 0.524 & $<0.001$ \\
Aortic distensibility & -0.436 & 0.003 \\
Sa0 & -0.582 & $<0.001$ \\
TC & 0.631 & $<0.001$ \\
LDL-C & 0.653 & $<0.001$ \\
\hline
\end{tabular}

Sao: systolic aortic upper wall velocity; TC: total cholesterol; LDL-C: low-density lipoproteincholesterol; TSH: thyroid stimulating hormone; SCH: subclinical hypothyroidism.

\section{DISCUSSION}

The findings of our study demonstrated that patients with SCH have higher stiffness index, lower distensibility of the ascending aorta, and lower Sao than the controls.

The pulse wave is observable and measurable in an arterial system throughout the circulation. During the cardiac systole, a certain volume of blood is ejected and propagates via arteries due to the transformation of kinetic to potential energy in each segment of ejected blood. In each site, the pulse wave progresses, pressure and blood flow velocity change, and ultimately, aortic wall activities are observed $(6,25)$. Thus, aortic wall movements, which bring about differentiation in the diameter of the proximal aortic lumen, enable us capture images of the changes in aortic elastic properties $(14-17,25)$. Arterial stiffness index determines the elastic properties of the arterial wall, in a manner relatively independent of blood pressure, and aortic distensibility evaluates the ability of the arteries to dilate during the cardiac cycle, and measures the function of the artery $(6,7,25)$.

Aortic stiffness and aortic distensibility have been examined with some methods, such as VVI and pulse wave velocity (PWV) $(12,26)$. However, VVI is a new and invasive method, requiring transesophageal echocardiography, which limits its routine clinical practice. Also, PWV is not the ideal procedure to evaluate aortic elasticity properties since it is affected by many factors including hematological and physiological characteristics, as well as heart rate and blood pressure variations (27-29).

The change in the diameter of the aorta detected by echocardiography can be related to the distending pressure and provides a measure of stiffness. However, this echocardiographic method of determining aortic stiffness using mathematical equations may have some limitations $(30,31)$. First, blood pressure and pulse pressure estimated at the level of brachial artery may not exactly reflect aortic pulse pressure. Secondly, blood pressure measurement and aortic echocardiographic assessment cannot be carried out simultaneously.

Direct measurement of aortic elasticity by TDI, which is a practical method for the measurement of diameter changes related to wall movements, may provide further help than other methods described above, because it is not affected by hematological and cardiovascular physiology. A number of studies have shown that elastic properties of the ascending aorta could be directly and reproducibly evaluated by measuring aorta movements in patients with CAD, DM, and hypertension (HT) by TDI (14-17). To our knowledge, the 
present study is the first one assessing elasticity indices of the ascending aorta using TDI in patients with $\mathrm{SCH}$.

Elastic properties and wall movements of the ascending aorta can be affected by several risk factors, such as aging and smoking status $(6,8,9)$. However, these risk factors cannot account for the differences in aortic stiffness obtained in the present study, because the distributions of these parameters were the same for both groups. Also, it is known that DM and HT have an unfavorable effect on arterial stiffness $(15,16)$ and, accordingly, diabetic and hypertensive patients were not recruited in the presented study. Thus, in the current trial, none of these risk factors appeared to influence arterial stiffness.

Dyslipidemia may cause some alterations in the elasticity of arterial wall, such as increase in central pulse pressure and endothelial dysfunction $(6,32)$. In addition, several reports in the literature indicate that $\mathrm{SCH}$ is associated with atherogenic lipid profile $(33,34)$. Similar to these results, we found that serum TC and LDL-C were significantly elevated in patients with $\mathrm{SCH}$ compared with euthyroid subjects. Also, we found significant positively correlation between serum TSH levels, and $\mathrm{TC}$ and LDL-C values in patients with $\mathrm{SCH}$, which is in line with the findings of study by Gen and cols. (34). Although no correlation was found between the stiffness index or distensibility and lipid values, a significant correlation was observed between stiffness index (positive) or distensibility (negative) and TSH values. The most plausible explanation for this association is that TSH may have a direct effect on the arterial wall.

Endothelial-dependent vasodilation is inversely correlated with the administration of recombinant human TSH and serum TSH levels $(35,36)$. In concordance with the results of these trials, our findings made us think that high TSH concentration may make SCH patients more prone to dyslipidemia and endothelial dysfunction, and thus, lead to impaired wall movements in the ascending aorta.

One of the important findings of our study was the reduced Sao, Eao, and Aao in patients with $\mathrm{SCH}$ compared with controls. From these measurements, only the decrease in Sao reached statistically significance. Moreover, we also found a negative correlation between Sao and aortic stiffness index and TSH value, and a positive correlation between Sao and distensibility. Reduced Sao is associated with arterial stiffness in patients with CAD and type-1 DM $(14,15)$, a finding consistent with the results of the current trial. During the cardiac cycle, the wave profile observed in the aortic wall movements has the same shape as the one found for the ventricle pa- rallel to the pressure changes in the aortic lumen, that is, Sao is observed while ventricle contracts, and Eao and Aao occured during ventricular diastole $(6,14,15)$. Another important point is whether Sao derives from the movement of the aorta or myocardial activation. Since we found no correlation between Sao and mitral annulus ( $\mathrm{Sm}, \mathrm{Em}, \mathrm{Am})$ velocities, we consider that Sao originates from aortic wall activities. Therefore, all these findings suggest that $\mathrm{SCH}$ may make the aortic wall dilate less during ventricular systole, as a consequence of stiffness observed in the ascending aorta.

A variety of studies have shown that arterial stiffness is the most significant reason for cardiovascular complications, and that decreased elasticity of the aorta could be attributed to the presence of atherosclerotic lesions in the aortic wall, even in the absence of evident cardiovascular disease $(6,7,9)$. Thus, impairment of arterial wall elasticity may pave the way for atherosclerosis.

The knowledge about the relationship between cardiovascular disease and $\mathrm{SCH}$ shows conflicting information. The most convincing data supporting greater cardiovascular risk in patients with $\mathrm{SCH}$ come from several recent meta-analyses, in which $\mathrm{SCH}$ has been reported to be associated with an elevated risk of cardiovascular disease and mortality $(4,5)$. Moreover, some studies have demonstrated that patients with SCH had increased brachial-ankle PWV, a useful index of arterial stiffness, and increased carotid arterial stiffness, a useful predictor of cardiovascular risk (18-20). Elevated arterial stiffness and reduced Sao are important predictors of CAD (14). Based on these data and our findings, it can be concluded that SCH could have a deleterious effect on vascular elasticity, and hence, could be an important risk factor for atherosclerosis by means of the mechanisms discussed above.

The present study had several limitations. The most important one was the small number of patients, which eliminate the ability to apply subgroup analysis according to the levels of TSH and/or the severity of SCH. The second limitation was the absence of data after normalization of SCH with levothyroxine treatment. Another limitation was that cardiac catheterization had not been carried out in our study population to exclude CAD and to evaluate intraventricular pressure, which may influence aortic wall TDI. This limitation can be omitted because it would be difficult, due to ethical concerns, to perform an invasive procedure in asymptomatic individuals with normal exercise stress echo results, as well as similar stroke volume obtained by echocardiography in both groups.

In conclusion, we found that patients with $\mathrm{SCH}$ had impaired aortic elastic properties, when compared with 
euthyroid control subjects. Reduced Sao was associated with the increased aortic stiffness, lipid profiles, and TSH levels. We also concluded that elastic properties of the ascending aorta evaluated by TDI are simple and practical to determine the level of stiffness of the aorta in patients with $\mathrm{SCH}$.

Disclosure: no potential conflict of interest relevant to this article was reported.

\section{REFERENCES}

1. Surks MI, Ortiz E, Daniels GH, Sawin CT, Col NF, Cabin RH, et al. Subclinical thyroid disease. Scientific review and guidelines for diagnosis and management. JAMA. 2004;291:228-38.

2. Canaris GJ, Manowitz NR, Mayor G, Ridgway EC. The Colorado thyroid disease prevalence study. Arch Intern Med. 2000;160:526-34.

3. Hollowell JG, Staehling NW, Flanders WD, Hannon WH, Gunter EW, Spencer CA, et al. Serum TSH, T4, and thyroid antibodies in the United States population (1988 to 1994): National Health and Nutrition Examination Survey (NHANES III). J Clin Endocrinol Metab. 2002;87:489-99.

4. Ochs N, Auer R, Bauer DC, Nanchen D, Gussekloo J, Cornuz J, et al. Meta-analysis: subclinical thyroid dysfunction and the risk for coronary heart disease and mortality. Ann Intern Med. 2008;148:832-45.

5. Imaizumi M, Akahoshi M, Ichimaru S, Nakashima E, Hida A, Soda $M$, et al. Risk for ischemic heart disease and all-cause mortality in subclinical hypothyroidism. J Clin Endocrinol Metab. 2004;89:3365-70.

6. Wagenseil JE, Mecham RP. Vascular extracellular matrix and arterial mechanics. Physiol Rev. 2009;89:957-89.

7. McEniery CM, Wilkinson IB, Avolio AP. Does arterial stiffness predict atherosclerotic coronary events? Clin Exp Pharmacol Physiol. 2007;34:665-71.

8. O'Rourke MF, Hashimoto J. Mechanical factors in arterial aging: a clinical perspective. J Am Coll Cardiol. 2007;50:1-13.

9. Malayeri AA, Natori S, Bahrami H, Bertoni AG, Kronmal R, Lima $J A$, et al. Relation of aortic wall thickness and distensibility to cardiovascular risk factors (from the multi-ethnic study of atherosclerosis [MESA]). Am J Cardiol. 2008;102:491-6.

10. Stefanadis C, Stratos C, Vlachopoulos C, Marakas S, Boudoulas $\mathrm{H}$, Kallikazaros I, et al. Pressure-diameter relation of the human aorta. A new method of determination by the application of a special ultrasonic dimension catheter. Circulation. 1995;92:2210-9.

11. Chen $\mathrm{CH}$, Ting $\mathrm{CT}$, Nussbacher $\mathrm{A}$, Nevo $\mathrm{E}$, Kass DA, Pak $\mathrm{P}$, et al. Validation of carotid artery tonometry as a means of estimating augmentation index of ascending aortic pressure. Hypertension. 1996;27:168-75.

12. Kim KH, Park JC, Yoon HJ, Yoon NS, Hong YJ, Park HW, et al. Usefulness of aortic strain analysis by velocity vector imaging as a new echocardiographic measure of arterial stiffness. J Am Soc Echocardiogr. 2009;22:1382-8.

13. Martins RM, Fonseca RHA, Duarte MMT, Reuters VS, Ferreira MM, Almeida C, et al. Impact of subclinical hypothyroidism treatment in systolic and diastolic cardiac function. Arq Bras Endocrinol Metab. 2011;55:460-7.

14. Eryol NK, Topsakal R, Cicek Y, Abacı A, Oguzhan A, Basar E, et al. Colour Doppler tissue imaging in assessing the elastic properties of the aorta and in predicting coronary artery disease. Jpn Heart J. 2002;43:219-30.

15. Karamitsos TD, Karvounis HI, Didangellos TP, Papadopoulos CE, Dalamanga EG, Karamitsos DT, et al. Usefulness of colour tissue Doppler imaging in assessing aortic elastic properties in type 1 diabetic patients. Diabet Med. 2006;23:1201-6.
16. Vitarelli A, Giordano M, Germano G, Pergolini M, Cicconetti P, Tomei $F$, et al. Assessment of ascending aorta wall stiffness in hypertensive patients by tissue Doppler imaging and strain Doppler echocardiography. Heart. 2010;96:1469-74.

17. Ozhan H, Yazıcı M, Albayrak S, Erbilen E, Bulur S, Akdemir R, et al. Elastic properties of the ascending aorta and left ventricular function in patients with hypothyroidism. Echocardiography. 2005;22:649-56.

18. Nagasahi T, Inaba M, Kumeda M, Hiura $Y$, Shirakawa K, Yamada $\mathrm{S}$, et al. Increased pulse wave velocity in subclinical hypothyroidism. J Clin Endocrinol Metab. 2006;91:154-8.

19. Valentina VN, Marijan B, Chedo D, Branka K. Subclinical hypothyroidism and risk to carotid atherosclerosis. Arq Bras Endocrinol Metab. 2011;55:475-80.

20. Tian L, Gao C, Liu J, Zhang X. Increased carotid arterial stiffness in subclinical hypothyroidism. Eur J Intern Med. 2010;21:560-3.

21. Devereux RB, Reichek N. Echocardiographic determination of left ventricular mass in man: Anatomic validation of the method. Circulation. 1977;55:613-7.

22. DuBois D, DuBois EF. Clinical calorimetry: a formula to estimate the approximate surface area if height and weight be known. Arch Intern Med. 1916;17:863-71.

23. Devereux RB. Detection of left ventricular hypertrophy by M-mode echocardography. Anatomic validation, standardization, and comparison to other methods. Hypertension. 1987;9:II19-26.

24. Friedewald WT, Levy RI, Fredrickson DS. Estimation of the concentration of low density lipoprotein in plasma, without use of the preparative ultracentrifuge. Clin Chem. 1972;18:499-502.

25. Korpas D, Halec J. Pulse wave variability within two short-term measurements. Biomed Pap Med Fac Univ Palacky Olomouc Czech Repub. 2006;150:339-44.

26. Asmar R, Benetos A, Topouchian J, Laurent P, Pannier B, Brisac $A M$, et al. Assessment of arterial distensibility by automatic pulse wave velocity measurement. Validation and clinical application studies. Hypertension. 1995;26:485-90.

27. Bia D, Aguirre I, Zocalo Y, Devera L, Cabrera Fischer E, Armentano R. [Regional differences in viscosity, elasticity and wall buffering function in systemic arteries: pulse wave analysis of the arterial pressure-diameter relationship]. Rev Esp Cardiol. 2005;58:167-74.

28. Lehmann ED. Noninvasive measurements of aortic stiffness: methodological considerations. Pathol Biol. 1999;47:716-30.

29. Lantelme P, Mestre C, Lievre M, Gressard A, Milon H. Heart rate. An important confounder of pulse wave velocity assessment. Hypertension. 2002;39:1083-7.

30. Benetos A, Laurent S, Hoeks AP, Boutouyrie PH, Safar ME. Arterial alterations with ageing and high blood pressure: a non-invasive study of carotid and femoral arteries. Arterioscler Thromb. 1993;13:90-7.

31. O'Rourke M, Frohlich ED. Pulse pressure: is it a clinically useful risk factor? Hypertension. 1999;34:372-4.

32. Plana N, Ferre R, Merino J, Aragones G, Girona J, Hears M, et al. Heterozygous familial hypercholesterolaemic patients have increased arterial stiffness, as determined using the augmentation Index. J AtherosclerThromb. 2011;18:1110-6.

33. Duntas LH, Mantzou E, Koutras DA. Circulating levels of oxidized low-density lipoprotein in overt and mild hypothyroidism. Thyroid. 2002;12:1003-7.

34. Gen R, Akbay E, Sezer K. Insulin resistance and cardiovascular risk factors in patients with mild and severe subclinical hypothyroidism. Endocrinologist. 2010;20:128-30.

35. Dardano A, Ghiadoni L, Plantinga Y, Caraccio N, Bemi A, Duranti $E$, et al. Recombinant human thyrotropin reduces endothelium-dependent vasodilation in patients monitored for differentiated thyroid carcinoma. J Clin Endocrinol Metab. 2006;91:4175-8.

36. Taddei S, Carraccio N, Virdis A, Dardano A, Versari D, Ghiadoni L, et al. Impaired endothelium-dependent vasodilation in subclinical hypothyroidism: beneficial effect of levothyroxine therapy. $J$ Clin Endocrinol Metab. 2003;88:3731-7. 